\title{
Aggregation Kinetics of Hematite Particles in the Presence of Outer Membrane Cytochrome OmcA of Shewanella oneidenesis MR-1
}

\author{
Anxu Sheng ${ }^{\mathrm{a}, \dagger}$, Feng Liu ${ }^{\mathrm{a}, \dagger}$, Liang Shi ${ }^{\mathrm{b}, \mathrm{c}}$, Juan Liu ${ }^{\mathrm{a}, *}$

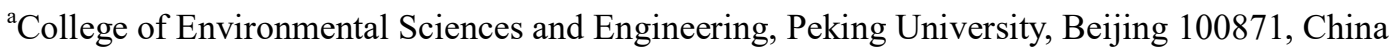 \\ ${ }^{\mathrm{b}}$ Department of Biological Sciences and Technology, School of Environmental Studies, China \\ University of Geoscience in Wuhan, Hubei, 430074, China \\ ${ }^{\mathrm{c}}$ Pacific Northwest National Laboratory, Richland, WA 99352, USA \\ * Corresponding Author: \\ Phone: +86-10-62754292-808 \\ Email: juan.liu@pku.edu.cn
}

10 Pages

\section{Sections \\ 1 Table \\ 7 Figures}




\section{Section S1. Hematite synthesis:}

The $9 \mathrm{~nm}$ hematite nanoparticles (NPs) were synthesized by slowing adding $80 \mathrm{~mL}$ of $1 \mathrm{M}$ $\mathrm{Fe}\left(\mathrm{NO}_{3}\right)_{3} \cdot 9 \mathrm{H}_{2} \mathrm{O}$ into $1 \mathrm{~L}$ boiling distilled MilliQ water at the speed of $0.5 \mathrm{~mL} / \mathrm{min}$ and stirring vigorously. After the addition was finished, the resulting suspension was removed from the heat to cooled overnight. For the synthesis of $36 \mathrm{~nm}$ hematite NPs, $500 \mathrm{~mL}$ of $0.002 \mathrm{M} \mathrm{HCl}$ solution in a screw-cap bottle was heated in a thermostatted oven at $98{ }^{0} \mathrm{C}$ overnight. Then, $4.04 \mathrm{~g}$ of $\mathrm{Fe}\left(\mathrm{NO}_{3}\right)_{3} \cdot 9 \mathrm{H}_{2} \mathrm{O}$ was added to the solution. The bottle was the closed and vigorously shaken. After that, it was returned to the oven immediately and held at $98{ }^{0} \mathrm{C}$ for 7 days. The two synthesis suspensions were dialyzed in standard grade Cellulose dialysis membrane (1000 MWCO, Spectra Por) against MilliQ water until the conductivity remained constant. For $112 \mathrm{~nm}$ hematite NPs synthesis, $0.001 \mathrm{M} \mathrm{HCl}$ solution (2L) was heated to $98^{\circ} \mathrm{C}$ in a closed polypropylene bottle, and then $\mathrm{FeCl}_{3}$ was added to it. The final concentration of $\mathrm{FeCl}_{3}$ is $0.04 \mathrm{M}$. After the bottle was tightly capped and vigorously shaken, the closed bottle was held at $98{ }^{\circ} \mathrm{C}$ in an oven for ten days. The resulting red suspensions were centrifuged and resuspended by sonication in DDW for 3 repetitions. All the synthetic NPs stock solutions were stored at $4{ }^{\circ} \mathrm{C}$ in dark. 
Table S1 Characteristics of synthetic hematite particles

\begin{tabular}{cccc}
\hline Sample & $\begin{array}{c}\text { Primary Particle size } \\
(\mathrm{nm})\end{array}$ & $\begin{array}{c}\text { Geometric specific } \\
\text { surface area }\left(\mathrm{m}^{2} / \mathrm{g}\right)\end{array}$ & Zeta potential $(\mathrm{mV})^{1}$ \\
\hline HM1 & $9 \pm 2$ & 127 & $24.87 \pm 0.70$ \\
\hline HM2 & $36 \pm 6$ & 32 & $24.08 \pm 1.19$ \\
\hline HM3 & $112 \pm 12$ & 10 & $30.58 \pm 0.52$ \\
\hline
\end{tabular}

${ }^{1}$ Zeta potentials were determined in $5 \mathrm{mM} \mathrm{NaCl}$ at $\mathrm{pH} 5.7$. 

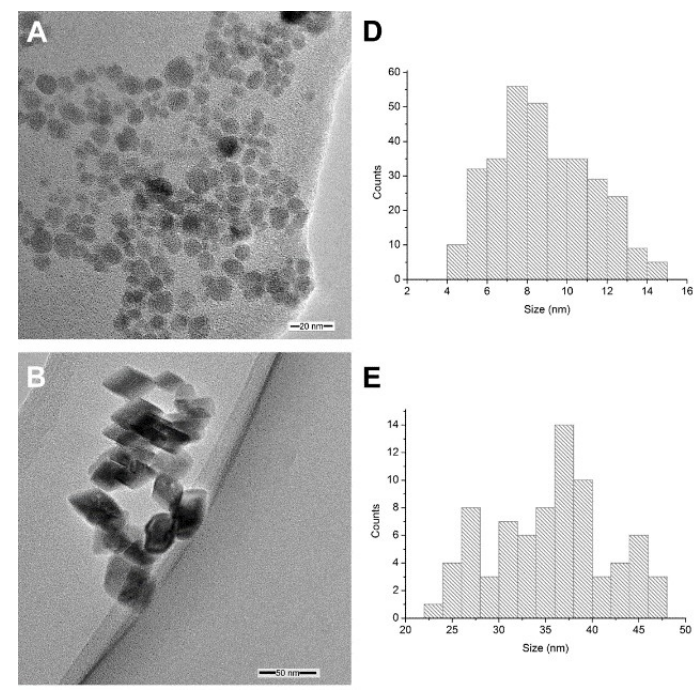

E
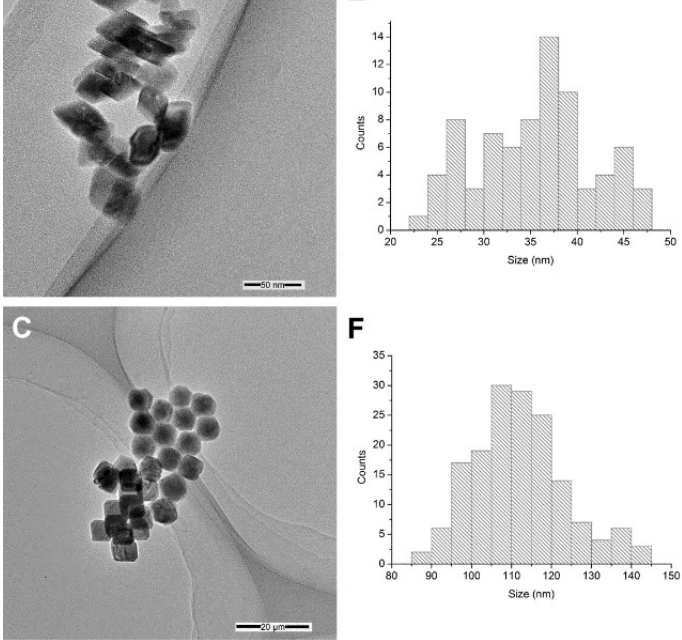

Figure S1. Transmission electron microscopy (TEM) images of HM1 (A), HM2 (B), and HM3 (C). The size distributions of HM1 (D), HM2 (E), and HM3 (F) show that their primary particle sizes are $9 \pm 2 \mathrm{~nm}$ (one standard deviation), $36 \pm 6 \mathrm{~nm}$, and $112 \pm 12 \mathrm{~nm}$, respectively. 


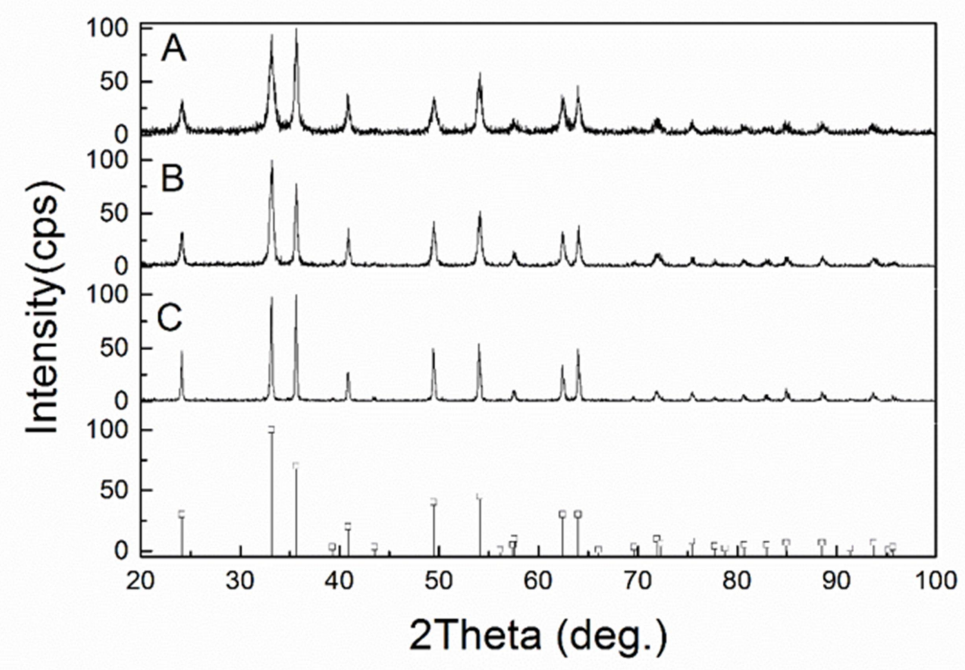

Figure S2. XRD patterns of three synthetic hematite particles: HM1 (A), HM2 (B), and HM3 (C) (above) with the hematite reference (below, JCPDS No.33-0664) 
(a)
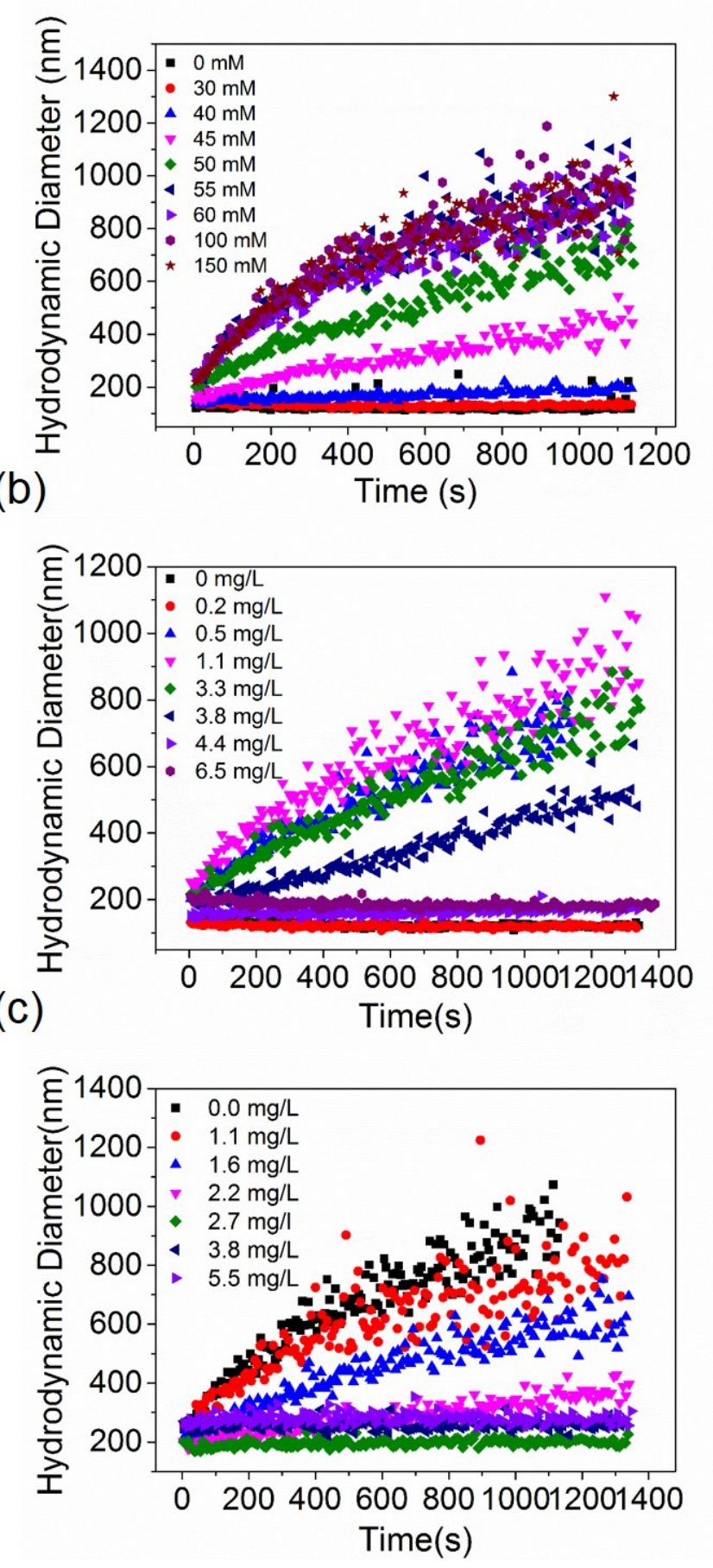

Figure S3. Aggregation profiles of $16 \mathrm{mg} / \mathrm{L}$ bare HM1 NPs with varied $\mathrm{NaCl}$ concentrations $(0-150 \mathrm{mM})$ (a), $16 \mathrm{mg} / \mathrm{L}$ HM1 NPs conjugated with 0 - $6.5 \mathrm{mg} / \mathrm{L}$ OmcA in $10 \mathrm{mM} \mathrm{NaCl}$ (b), and $16 \mathrm{mg} / \mathrm{L}$ HM1 NPs conjugated with $0-5.5 \mathrm{mg} / \mathrm{L}$ OmcA in $60 \mathrm{mM} \mathrm{NaCl}$ (c). 


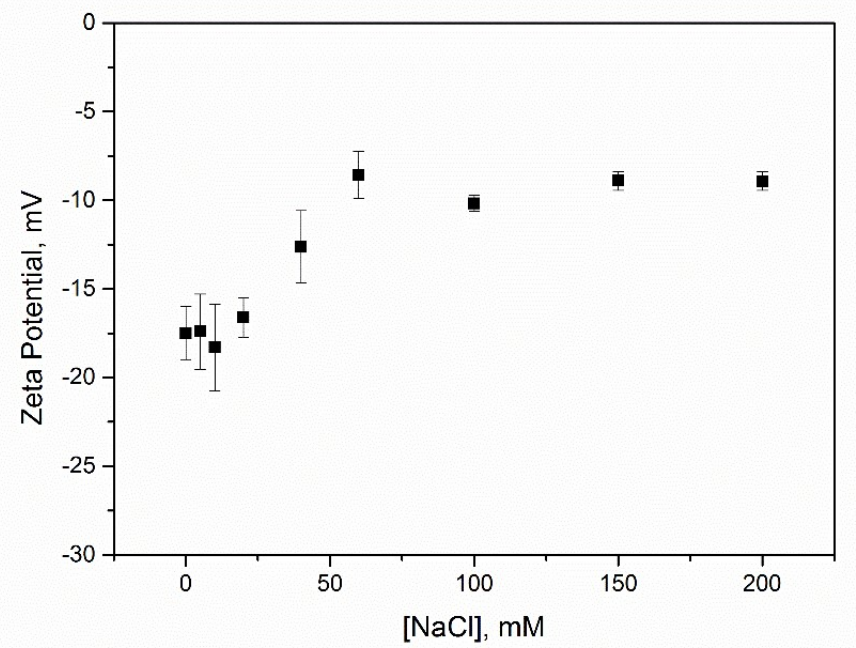

Figure S4. Zeta potentials of OmcA $(2.7 \mathrm{mg} / \mathrm{L})$ versus $\mathrm{NaCl}$ concentration at $\mathrm{pH} 5.7$. 


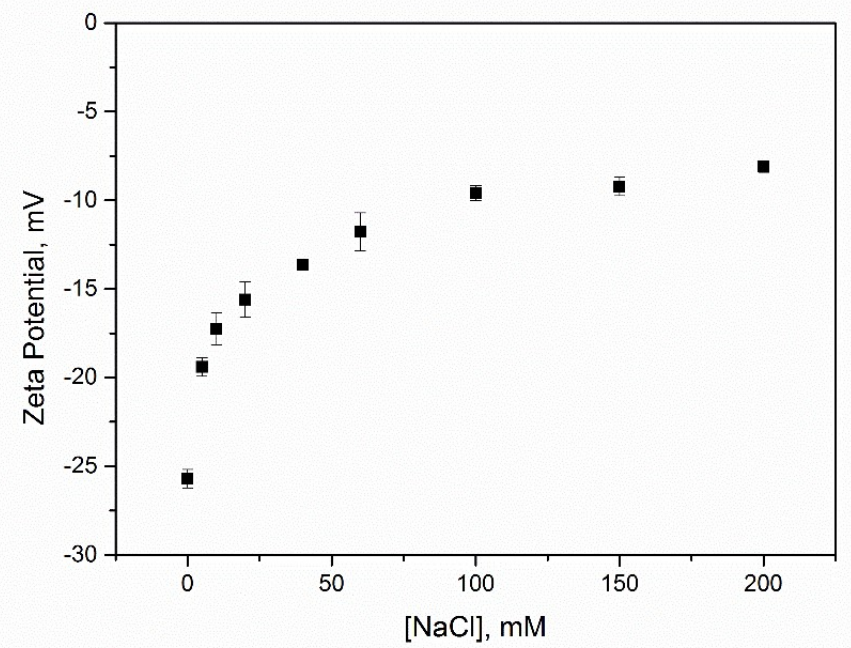

Figure S5. Zeta potential of $16 \mathrm{mg} / \mathrm{L} \mathrm{HM} 1 \mathrm{NPs}$ in the presence of $2.7 \mathrm{mg} / \mathrm{L} \mathrm{OmcA}$ as a function of $\mathrm{NaCl}$ concentration at $\mathrm{pH}$ 5.7. 


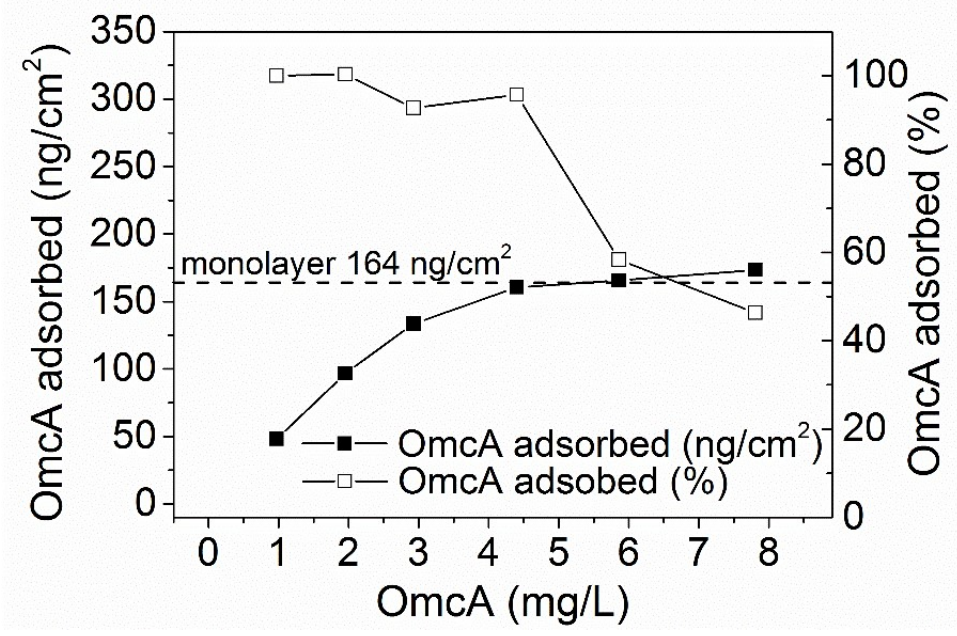

Figure S6. Adsorption isotherms of OmcA on $16 \mathrm{mg} / \mathrm{L}$ HM1 NPs plotted as a function of protein concentration added in $10 \mathrm{mM} \mathrm{NaCl}$ solution at $\mathrm{pH}$ 5.7. The solid dots represent the concentration of proteins adsorbed on HM1 NPs, and the open dots represent the adsorption percentage of added proteins. 
(a)

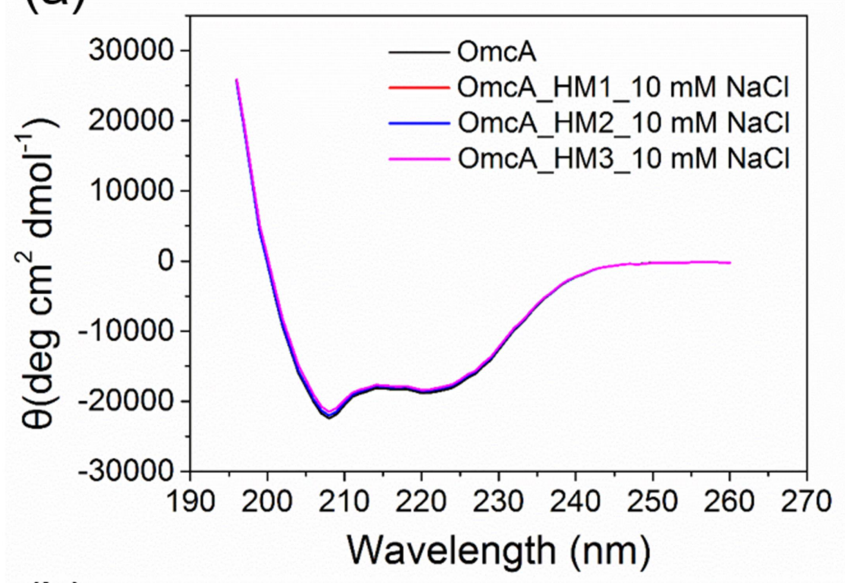

(b)

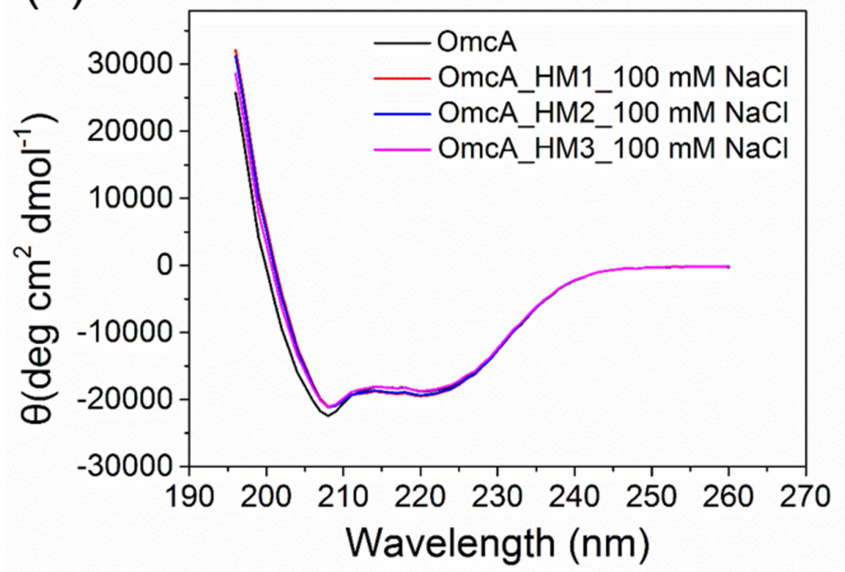

(c)

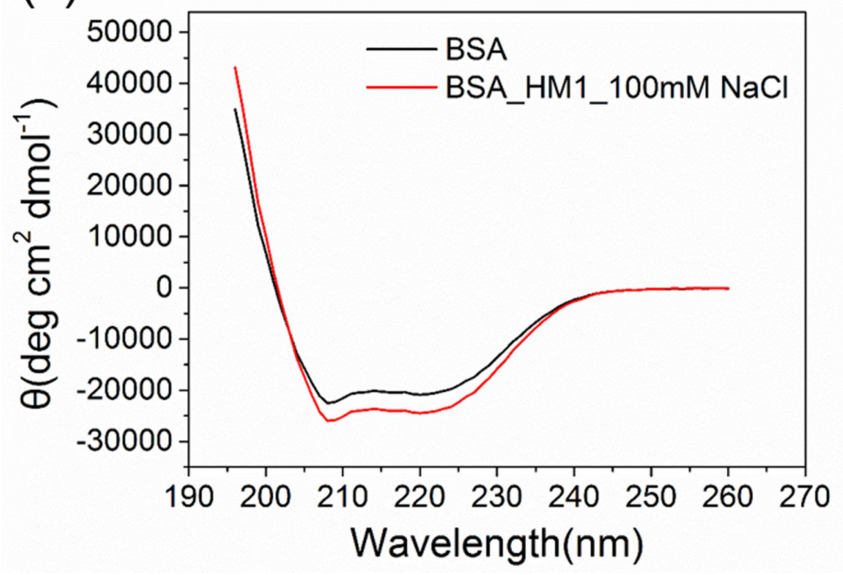

Figure S7. Circular dichroism spectra of native OmcA and OmcA conjugated with 16mg/L HM1 NPs in 10 $\mathrm{mM} \mathrm{NaCl}$ (a) and $100 \mathrm{mM} \mathrm{NaCl}$ (b), respectively. (c) Circular dichroism spectra of native BSA and BSA conjugated with 16mg/L HM1 NPs in $100 \mathrm{mM} \mathrm{NaCl}$. 